\title{
O CRIME DE AGRESSÃO NA COMPETÊNCIA RATIONE MATERIÆE DO TRIBUNAL PENAL INTERNACIONAL
}

\author{
Danny Renan Mineguel Assis ${ }^{1}$
}

\section{RESUMO}

A inclusão do crime de agressão na competência material do Tribunal Penal Internacional segue uma lógica de compatibilidade com o desenvolvimento do Direito Penal Internacional. Porém, essa é uma inclusão de iure e não de facto, uma vez que não foi possível se alcançar um consenso sobre sua definição devido à natureza complicada do crime. Este abrange a responsabilidade individual e pressupõe o cometimento de agressão pelo Estado. Por este motivo a atuação do Conselho de Segurança na determinação da existência de agressão, como previsto pela Carta da Organização das Nações Unidas, é uma das questões mais controvertidas que não foram ainda solucionadas. Talvez uma influência com tal natureza política estaria em contradição com as idéias de autonomia e imparcialidade do Tribunal e iria, então, contra seus objetivos fundamentais.

\section{INTRODUÇÃO}

Durante o período de 15 de junho a 17 de julho de 1998, em território italiano, foi realizada a Conferência Diplomática de Roma, na qual se discutiu os temas relativos à implementação de uma corte penal, de caráter complementar às jurisdições nacionais, capaz de julgar os indivíduos responsáveis pelos crimes mais graves no âmbito internacional. Na ocasião, promulgou-se o Estatuto de Roma, tratado internacional do Tribunal Penal Internacional, que iria se instalar somente em 2002.

Um dos temas talvez mais controversos durante a Conferência foi a inclusão e definição do crime de agressão no Estatuto de Roma. Devido à pluralidade de interesses dos países presentes não se chegou a um acordo

\footnotetext{
1 Acadêmico de direito da UFPR e pesquisador do Núcleo de Estudos em Direito Internacional da UFPR.
}

Revista Brasileira de Direito Internacional, Curitiba, v.1, n.1, jan./jun.2005 
sobre a definição do crime. Dessa forma, algumas delegações se posicionaram contra sua inclusão no rol de crimes; outras, porém, acreditando que seria um retrocesso instaurar uma corte de tal magnitude em que não se incluísse um crime tão importante como esse e que data de longo tempo no Direito Internacional Penal, defendiam que se devia incluir o crime de agressão na competência material do Tribunal. Pela escassez de tempo, pela necessidade de se discutirem outros temas e pelo empasse na definição do crime de agressão, o Presidente da Sessão, o canadense Kirsch, propôs a seguinte solução: incluir agressão no Estatuto de Roma prevendo-se sua posterior definição, a partir de quando o TPI passaria ter competência sobre tal crime, ou seja, uma inclusão de iure mas não de facto. Não havendo possibilidade de se terminar a Conferência com tal definição pela escassez de tempo, optou-se por essa solução, dando-se a seguinte redação ao parágrafo $2^{\circ}$ do artigo $5^{\circ}$ do Estatuto de Roma:

O Tribunal exercerá jurisdição em relação ao crime de agressão uma vez que se aprove uma disposição de conformidade com os artigos 121 e 123 na qual se defina o crime e se enunciem as condições nas quais o fará. Essa disposição será compatível com as disposições pertinentes à Carta das Nações Unidas. ${ }^{2}$

É válido lembrar que o artigo 121 disciplina o regime de emendas ao Estatuto. Por sua vez, o artigo 123 prevê que após 7 anos da entrada em vigor do Estatuto de Roma haverá uma Conferência de Revisão para se examinar as emendas feitas ao Estatuto (ou seja, essa revisão não incidirá necessariamente só ao rol de crimes).

Mesmo tendo-se achado uma solução momentânea para o problema, há que se recordar que o problema não está, todavia, sanado. É extremamente necessário que em 2009 (o Estatuto entrou em vigor em 1ํ de julho de 2002) os Estados Partes já tenham chegado a um consenso, ainda que informal,

\footnotetext{
2 Tradução livre de: "La Corte ejercerá competencia respecto del crimen de agresión una vez que se apruebe una disposición de conformidad con los artículos 121 y 123 en que se defina el crimen y se enuncien las condiciones en las cuales lo hará. Esa disposición será compatible con las disposiciones pertinentes de la Carta de las Naciones Unidas."
}

Revista Brasileira de Direito Internacional, Curitiba, v.1, n.1, jan./jun.2005 
sobre a definição do crime de agressão para que não se tomem outra vez medidas só momentaneamente solucionadoras.

Como se trata de um tema de pouca discussão na doutrina brasileira, pretende-se com este trabalho delinear um panorama geral sobre 0 desenvolvimento histórico do conceito do crime de agressão, expor suas principais características, apresentar algumas propostas feitas durante a Conferência, bem como apresentar conclusões sobre uma futura definição.

Revista Brasileira de Direito Internacional, Curitiba, v.1, n.1, jan./jun.2005 


\section{COMPETÊNCIA RATIONE MATERIAE DO TPI}

Conforme 0 artigo $1^{\circ}$ do Estatuto de Roma, o TPI tem competência para julgar pessoas, no que diz respeito aos crimes mais graves em âmbito internacional, nas hipóteses de o réu ser nacional de um Estado Parte ou de o crime ter ocorrido no território de um Estado Parte (ou a bordo de aeronave e navio cuja propriedade ou matrícula é de um Estado Parte) $)^{3}$. O TPI poderá exercer competência sobre os crimes caso o Conselho de Segurança ou qualquer Estado Parte remeta o caso ao Procurador e caso se o Procurador houver iniciado investigações sobre uma determinada situação. Para os Estados não-Partes que aceitem a jurisdição da Corte apenas em relação a um caso específico (e para aqueles fins), só haverá competência sobre os crimes, locais e datas referentes a essa aceitação. Além disso, a competência ratione temporis é a partir da entrada em vigor do Estatuto (após o sexagésimo depósito de ratificação), e para Estado que se torna Parte posteriormente à entrada em vigor do Estatuto, o TPI exercerá competência aos crimes posteriores a essa entrada, a exceção a essa regra diz respeito exatamente à forma ad hoc do Tribunal agir citada acima.

O Estatuto de Roma prevê no artigo 5ำ parágrafo 1, Capítulo II/Parte II (Competência, Admissibilidade e Direito Aplicável), que o TPI exercerá jurisdição sobre o crime de genocídio, os crimes contra a humanidade (de lesa humanidade), os crimes de guerra e o crime de agressão. Muitas ONGs e algumas delegações que acompanharam o desenvolvimento da Conferência sustentavam a opinião de que outros crimes, como o tráfico internacional de drogas e terrorismo, também se encaixavam no conceito de crimes de maior gravidade na seara internacional, os quais seriam então do âmbito de atuação do TPI. Porém, com o andamento das discussões e pluralidade de interesses, viu-se que seria preferível incluir um número reduzido de crimes no Estatuto (ou seja, só os realmente mais graves) e abarcar dessa maneira um número maior de países, dotando assim o TPI de uma maior eficácia, a inchar o rol de crimes e alcançar um número reduzido de países, deixando então para

Artigo 12 parágrafo 2 .

Revista Brasileira de Direito Internacional, Curitiba, v.1, n.1, jan./jun.2005 
futuramente se discutir sobre a possibilidade de novas inclusões (primeiramente solidificar para depois abranger); afinal, não se acolheu 0 sistema de opt out em relação aos crimes, haja vista o artigo 12 parágrafo 1ํ․ "O Estado que se torne Parte no presente Estatuto, aceitará a jurisdição do Tribunal relativamente aos crimes a que se refere o artigo".

A inclusão do genocídio foi menos controversa, ${ }_{1}$ uma vez que se trata de um crime com uma definição já solidificada no Direito Internacional Penal. Além disso, preferia-se evitar demasiado debate sobre questões nas quais já se havia alcançado um certo grau de consenso. A definição provém basicamente da Convenção de Genocídio de 1945. Os tribunais penais internacionais ad hoc para a ex-lugoslávia e para Ruanda também previram tal crime, de maneira semelhante, já que julgaram conflitos de origem basicamente étnico-política. É o artigo 6º que dentro do Capítulo II trata de tal crime. O texto com a definição de genocídio, para os fins do TPI, trazida pelo Estatuto de Roma é composto de duas partes. A primeira, no caput, traz o elemento da vontade: "com a intenção de destruir total ou parcialmente a um grupo nacional, étnico, racial ou religioso". A segunda parte se compõe de uma estrutura taxativa de atos que caracterizam a conduta criminosa. Ao mesmo tempo que se pretendia com uma enumeração mais abstrata não restringir 0 campo de abrangência do tipo, afinal é difícil prever todas as ações e situações específicas que se enquadram no conceito de genocídio, incorreu-se no problema da imprecisão. Fica incerta, e a cabo do juiz no caso concreto, a questão de se saber a quantidade de membros necessária para que se caracterize um grupo "apto" a ser perseguido dentro dos parâmetros do tipo penal estabelecido.

Os dois artigos seguintes no Estatuto, artigos 7 e 8 , tratam respectivamente dos crimes de lesa humanidade e dos crimes de guerra. Possuem basicamente a mesma estruturação. $O$ artigo dos crimes contra a humanidade é composto de 2 parágrafos divididos em alíneas. O texto do caput do primeiro parágrafo deve ser analisado em partes; a primeira delas, "parte de um ataque generalizado ou sistemático contra qualquer população civil, havendo conhecimento de tal ataque" tem o papel de limitar a 
competência do Tribunal, evitando que este venha a julgar casos motivados por razões alheias ao ataque em questão, não tenham alcançado proporções condizentes com seu propósito (expressas no Preâmbulo: "crimes de maior gravidade que afetam a comunidade internacional no seu conjunto") ou que não tenham sido objeto de prévia sistematização. Os incisos/alíneas trazem a descrição de todos os atos que podem ser considerados dentro do tipo (como por exemplo, "tortura", "deportação ou transferência à força de população" e "o crime de apartheid"); o segundo parágrafo traz um esclarecimento dos termos usados no primeiro. Não há a exigência de que haja conflito armado ou de que não seja em conflito armado, apenas de que os ataques se dirijam a populações civis ${ }^{4}$. Este entender vem desde o Tribunal Internacional para a exlugoslávia, quando a Câmara de Apelações proferiu o seguinte posicionamento no caso Tadic: "Já é uma regra sedimentada do Direito Internacional consuetudinário a não exigência de conexão de crimes contra a humanidade com conflitos armados internacionais. ${ }^{5}$

O artigo 8 possui estrutura semelhante ao anterior. E, igualmente aos crimes de lesa humanidade, provém de várias fontes do Direito Internacional (mas neste caso principalmente da Convenção de Genebra de 12 de agosto de 1949). Seu parágrafo $1\left(^{\circ}{ }^{\circ}\right)$ enfatiza a competência do TPI sobre crimes parte de um plano ou política ou como parte de uma comissão em larga escala. $O$ parágrafo seguinte relaciona taxativamente, e por isso de maneira extensa, todos os atos que podem caracterizar o tipo penal. Não há a exigência de que os conflitos armados sejam internacionais especificamente nos incisos/alíneas (c) e (e), o que é visto com bons olhos pela doutrina, afinal nem todas as atrocidades que ocorrem em conflitos armados são de caráter internacional, até porque acontecem com freqüência em guerra civil. Apesar do bom número de inclusões, lamenta-se a não proibição também de armas nucleares, minas e semelhantes.

\footnotetext{
$4 \quad$ Ver também artigo 7 parágrafo 2 inciso (a).

LAWYERS COMITEE FOR HUMANS RIGHT. Establishing an International Criminal Court: Major Unresolved Issues in the Draft Statute. Pág 25. Tradução livre de: "It is by now a settled rule of costumary international law that crimes against humanity do not require a connection to international armed conflict".
}

Revista Brasileira de Direito Internacional, Curitiba, v.1, n.1, jan./jun.2005 
Como já dito, o crime de agressão foi uma inclusão de jure mas não de facto, e o TPI só passará a ter competência sobre este crime quando houver sido feita sua definição para os fins do Tribunal (e condizentes com as disposições pertinentes da Carta da ONU). Tal tarefa ocorrerá em 2009 quando haverá uma Conferência de Revisão dos Estados Partes convocada pelo Secretário-Geral da Organização das Nações Unidas para se examinar as emendas ao Estatuto de Roma, conforme art 123.

Revista Brasileira de Direito Internacional, Curitiba, v.1, n.1, jan./jun.2005 


\section{EVOLUÇÃO DO CONCEITO DE AGRESSÃO}

Para Delbez, a guerra é "uma luta armada entre Estados, desejada ao menos por um deles e empreendida tendo em vista um interesse nacional"6. Para Albuquerque Mello, a guerra é um status jurídico, indo além da mera constatação do animus belligerandi (elemento subjetivo) e da prática dos atos de guerra (elemento objetivo).

A guerra sempre existiu na história da humanidade como um meio de resolução de conflitos (tanto que o Direito Internacional, nos seus primórdios, tratava basicamente dela). Ao mesmo tempo, a idéia de se limitar o uso da força data de longo tempo, uma vez que a sociedade internacional nem sempre consentiu com todas as guerras (nem ao menos considerou todas justas). $O$ eixo básico dessa idéia está na indagação da legalidade do uso da força posta por Gewehr: "o quanto pode um Estado legalmente impor força a outro Estado?"7. Trata-se da questão do jus ad bellum, o direito à guerra (diferentemente do jus in bello, que é o Direito que regula a guerra). O crime de agressão surge, portanto, com as idéia primordial dede guerra justa e injusta, para a qual ocorreria agressão quando se iniciasse injustamente uma guerra.

A noção de guerra justa inicia seu desenvolvimento doutrinário com a filosofia cristã na Idade Média. Inicialmente os filósofos desse período consideravam todas as guerras injustas. Num período posterior, passa-se a considerar o jus ad bellum como atributo tanto de particulares quanto de Estados. No final do Medievo, os príncipes passam a entender como justas todas as guerras atreladas às questões do reino. Ela passa a ser vista, então, como raison d'État, como continuação da política estatal. De tal maneira, todo Estado teria o direito de dar início a uma guerra sem cometer agressão contra outro Estado, afinal cada Estado definia os motivos que o levavam à guerra $\mathrm{e}$ esses a justificavam. Toda guerra iniciada por um Estado seria legal; porém, uma guerra iniciada por 'sujeitos' não estatais seria guerra injusta.

\footnotetext{
6 Delbez conforme ALBUQUERQUE MELLO, Celso Duvivier de. Curso de Direito internacional Público. pág 1412.

7 GEWEHR, Joachim. Defining Aggression for the International Criminal Court: A Proposal. Tradução livre de: "to what extent can a State lawfully inflict force on another State?".
}

Revista Brasileira de Direito Internacional, Curitiba, v.1, n.1, jan./jun.2005 
No século $X X$, pelo desenvolvimento cultural que a sociedade internacional sofreu e pelas experiências históricas que viveu, há uma mudança significativa no posicionamento sobre a questão. Surge uma desaprovação à guerra e à utilização da força como meio de solução de conflitos.

Com o advento da Primeira Guerra Mundial, o Convênio da Liga das Nações traz a seguinte definição em seu artigo 10: "respeitar e preservar a integridade territorial e independência política existente de cada membro contra agressão externa" ${ }^{8}$. Essa definição reflete essa posição diferente em relação à questão, os signatários de tal tratado passam a ver qualquer desrespeito à integridade territorial e independência como agressão e assim a guerra já não é mais um poder ou faculdade do Estado. No mesmo entender, legislou a Resolução de 1927 da Assembléia do mesmo órgão: "Uma guerra de agressão nunca pode servir como meio resolução de disputas internacionais, e é, conseqüentemente, um crime internacional". Tal documento estatui pela primeira vez a agressão como crime, sendo, portanto, um marco no Direito Internacional Penal.

Outro marco na matéria foi o Pacto de Paris, de 1928, que ficou conhecido como Pacto Briand-Kellogg9 ${ }^{9}$. Esse tratado definiu que qualquer guerra seria proibida (não só as de agressão), caindo por terra a teoria da guerra justa/injusta. Dizia seu artigo 10:

As Altas Partes Contratantes solenemente declaram, em nome de seus respectivos povos, que condenam o recurso à guerra para a solução de controvérsias internacionais e a ela renunciam como um instrumento de política nacional nas suas relações mútuas. ${ }^{10}$

\footnotetext{
$8 \quad$ Convênio da Liga das Nações art. 10

9 Aristide Briand era Ministro francês das Relações Exteriores e Frank B. Kellogg, Secretário de Estado norte-americano.

10 Pacto de Paris, artigo 1‥ Tradução livre de: "Les Hautes Parties Contractantes déclarent solennellement, au nom de leurs peuples respectifs, qu'elles condamnent le recours à la guerre pour le règlement des différends internationaux et y renoncent en tant qu'instrument de politique nationale dans leurs relations mutuelles."
}

Revista Brasileira de Direito Internacional, Curitiba, v.1, n.1, jan./jun.2005 
Porém, apesar de a guerra (de qualquer espécie) haver sido considerada como conduta ilícita e ilegal, não se tinha qualquer definição de ato e nem de crime de agressão.

A Carta da Organização das Nações Unidas de 1945 segue na mesma linha de pensamento do Pacto Briand-Kellogg. Seu artigo $1^{\circ}$ (tratando dos propósitos das Nações Unidas) traz a supressão dos atos de agressão:

\begin{abstract}
Manter a paz e a segurança internacionais e, para esse fim: tomar, coletivamente, medidas efetivas para evitar ameaças à paz e reprimir os atos de agressão ou outra qualquer ruptura de paz e chegar, por meios pacíficos e de conformidade com os princípios da justiça e do direito internacional, a um ajuste ou solução das controvérsias ou situações que possam levar a uma perturbação da paz. ${ }^{11}$
\end{abstract}

Da mesma forma faz o artigo $2^{\circ}$ nas alíneas 3 e 4 :

3 Todos os Membros, deverão resolver suas controvérsias internacionais por meios pacíficos, de modo que não sejam ameaçadas a paz, a segurança e a justiça internacionais.

4 Todos os Membros, deverão evitar em suas relações internacionais a ameaça ou o uso da força contra a integridade territorial ou a independência política de qualquer Estado, ou qualquer outra ação incompatível com os Propósitos das Nações Unidas. ${ }^{12}$

Também a Assembléia Geral atuou no desenvolvimento da definição do crime de agressão, aprovando em 14 de Dezembro de 1954 a Resolução 3314. Tal documento tinha a função de guiar o Conselho de Segurança na formulação de uma definição de agressão. Destaca-se um trecho do Preâmbulo, que mostra esse propósito:

Lembrando que o Conselho de Segurança, de acordo com o Artigo 39 da Carta das Nações Unidas, determinará a existência de qualquer ameaça à paz, ruptura de paz ou ato de agressão e recomendará, ou decidirá que medidas devem ser tomadas de acordo com os Artigos 41 e 42, para manter ou restabelecer a paz e segurança internacionais. ${ }^{13}$

\footnotetext{
$11 \quad$ Carta das Nações Unidas.

12 Carta das Nações Unidas.

13 Resolução 3314 da Assembléia Geral, Preâmbulo. Tradução livre de: "Recalling that the Security Council, in accordance with Article 39 of the Charter of the United Nations, shall determine the existence of any threat to the peace, breach of the peace or act of aggression and shall make recommendations, or decide what measures shall be taken in accordance with Articles 41 and 42, to maintain or restore international peace and security."
}

Revista Brasileira de Direito Internacional, Curitiba, v.1, n.1, jan./jun.2005 
Além de uma proposta de definição, traz uma lista de atos considerados como agressão:

\begin{abstract}
Artigo $1^{\circ}$ - Agressão é o uso de força armada por um Estado contra a soberania, integridade territorial ou independência política de outro Estado, ou em qualquer outra maneira inconsistente com a Carta das Nações Unidas, como apresentadas nesta Definição.
\end{abstract}

Nota explicativa: nesta Definição o termo "Estado":

(a) é usado sem prejuízo a questões de reconhecimento ou se um Estado é membro das Nações Unidas;

(b) inclui o conceito de "grupo" de Estados onde apropriado

Artigo $2^{\circ}$. Entre os atos que constituem agressão figuram os seguintes, precedidos ou não de uma declaração de guerra:

a) A invasão ou o ataque pelas forças armadas de um Estado do território de outro Estado, ou qualquer ocupação militar, por provisional que seja, resultante dessa invasão ou ataque, ou qualquer anexação mediante o uso da força do território de outro Estado ou parte de outro Estado;

b) $\mathrm{O}$ bombardeio por as forças armadas de um Estado contra o território de outro Estado, ou a utilização de quaisquer armas por um Estado contra o território de outro Estado;

c) O bloqueo de los puertos o costas de un Estado por las fuerzas armadas de otro Estado;

d) Um ataque pelas forças armadas de um Estado contra forças terrestres, navais ou aéreas, ou contra as frotas navais ou aéreas de outro Estado;

e) A utilização de forças armadas de um Estado que se encontre no território de outro Estado com o consentimento do Estado receptor em violação das condições previstas no acordo, o qualquer prolongação de sua presença nesse território para além do termo do acordo;

f) A ação de um Estado que autoriza que seu território, que pôs à disposição de outro Estado, seja utilizado por esse outro Estado para perpetrar um ato de agressão contra um terceiro Estado;

g) O envio por um Estado ou por sua conta de bandas armadas, grupos, tropas não regulares ou mercenários que realizem atos de força armada contra outro Estado de tal gravidade que equivalham aos atos enumerados acima ou sua participação substancial neles.

Artigo $4^{\circ}$ - Os atos enumerados acima não são exaustivos e $o$ Conselho de Segurança determinará que outros atos constituem agressão segundo as provisões da Carta. ${ }^{14}$

14 Resolução 3314 da Assembléia Geral. Tradução livre de:

"Article 1 - Aggression is the use of armed force by a State against the sovereignty, territorial integrity or political independence of another State, or in any other manner inconsistent with the Charter of the United Nations, as set out in this Definition.

Explanatory note: In this Definition the term "State":

(a) Is used without prejudice to questions of recognition or to whether a State is a member of the United Nations;

(b) Includes the concept of a "group of States" where appropriate

Article 3 - Any of the following acts, regardless of a declaration of war, shall, subject to and in accordance with the provisions of article 2, qualify as an act of aggression:

(a) The invasion or attack by the armed forces of a State of the territory of another State, or any military occupation, however temporary, resulting from such invasion or attack, or any annexation by the use of force of the territory of another State or part thereof,

(b) Bombardment by the armed forces of a State against the territory of another State or the use of any weapons by a State against the territory of another State;

(c) The blockade of the ports or coasts of a State by the armed forces of another State;

Revista Brasileira de Direito Internacional, Curitiba, v.1, n.1, jan./jun.2005 
Como se vê, a proposta não contribui especificamente no tocante à responsabilidade individual, porém há que se reconhecer seu mérito ao contribuir para a evolução do conceito de agressão e conseqüentemente da matéria.

Albuquerque de Mello afirma que "atualmente, com a renúncia à guerra, os Estados perderam, teoricamente, o 'jus ad bellum'. O uso da força armada está se tornando um monopólio da ONU e o seu emprego por ela não cria propriamente uma guerra, porque é apenas uma ação de política internacional"15. Isso condiz com as mudanças que o conceito de soberania vem sofrendo dentro quadro histórico e geopolítico contemporâneo.

(d) An attack by the armed forces of a State on the land, sea or air forces, or marine and air fleets of another State;

(e) The use of armed forces of one State which are within the territory of another State with the agreement of the receiving State, in contravention of the conditions provided for in the agreement or any extension of their presence in such territory beyond the termination of the agreement;

(f) The action of a State in allowing its territory, which it has placed at the disposal of another State, to be used by that other State for perpetrating an act of aggression against a third State;

(g) The sending by or on behalf of a State of armed bands, groups, irregulars or mercenaries, which carry out acts of armed force against another State of such gravity as to amount to the acts listed above, or its substantial involvement therein.

Article 4 - The acts enumerated above are not exhaustive and the Security Council may determine that other acts constitute aggression under the provisions of the Charter. ${ }_{15}$ ALBUQUERQUE MELLO, Celso Duvivier de. Curso de Direito internacional Público. pág 1418.

Revista Brasileira de Direito Internacional, Curitiba, v.1, n.1, jan./jun.2005 


\section{CARACTERÍSTICAS DO CRIME DE AGRESSÃo}

Inicialmente, é necessário fazer um esclarecimento terminológico dentro do tema: os termos ato de agressão, crime de agressão e guerra de agressão não são sinônimos. Os atos de agressão são os fatores materiais que identificam o cometimento de agressão. Agressão (guerra de agressão) constitui as investidas de um Estado contra outro agente estatal sem motivos que as justifiquem (contemporaneamente, esses fatores seriam uma autorização do Conselho de Segurança ou uma resposta em legítima defesa); a guerra de agressão é imputada a um Estado. O crime de agressão (antigamente chamado de crime contra a paz) é imputado aos responsáveis pelos atos da guerra de agressão. Para existir um crime de agressão é necessário imprescindivelmente haver ocorrido um ato de agressão; ou seja, para se imputar responsabilidade criminal ao sujeito que gerou a agressão relacionada ao Estado (e assim, cometeu o ilícito crime de agressão) é indispensável haver sido previamente determinada a agressão. Segundo Gewehr: "Agressão é um crime internacional que acarreta tanto a responsabilidade do Estado quanto responsabilidade criminal individual"16. Essa duplicidade referente ao crime de agressão é admitida no Direito Internacional desde a jurisprudência do Tribunal Internacional Militar (Tribunal de Nuremberg), quando se estabeleceu o princípio da responsabilidade individual:

Crimes contra o Direito Internacional são cometidos por homens, não por entidades abstratas, e somente punindo os indivíduos que cometem tais crimes pode-se reforçar as provisões do Direito Internacional. ${ }^{17}$

Segundo o artigo 39 da Carta da Organização das Nações Unidas, ao Conselho de Segurança compete a função de determinar a existência de atos

\footnotetext{
16 GEWEHR, Joachim. Defining Aggression for the International Criminal Court: A Proposal. Pág 6. Tradução livre de: Thus aggression is an international crime that entails both State responsibility and individual criminal responsibility.

17 Tribunal Internacional Militar segundo GEWEHR, Joachim. Defining Aggression for the International Criminal Court: A Proposal. Pág pág 13. Tradução livre de: "Crimes against International Law are comitted by men, not abstract entities, and only by punishing individuals who commit such crimes can the provisions of International Law be enforced."
}

Revista Brasileira de Direito Internacional, Curitiba, v.1, n.1, jan./jun.2005 
de agressão dentro da sua tarefa maior manutenção da paz e da segurança internacional:

O Conselho de Segurança determinará a existência de qualquer ameaça à paz, ruptura de paz ou ato de agressão, e fará recomendações ou decidirá que medidas deverão ser tomadas de acordo com os Artigos 41 e 42, a fim de manter ou restabelecer a paz, e a segurança internacionais. ${ }^{18}$

O papel do Conselho de Segurança dentro dessa determinação e conseqüentemente sua interferência dentro da atividade do Tribunal é o ponto central do debate. A Corte Internacional de Justiça, que tem competência sobre Estados, já lidou com casos de atos de agressão, e no caso Nicarágua decidiu que não necessitava de uma determinação prévia da existência de agressão pelo Conseho de Segurança.

Com respeito à competência em razão da pessoa do crime de agressão, a discussão gira em torno de se reservar o crime somente àquelas pessoas com poder e controle político e militar ou a todos os indivíduos que o cometem (como no caso do genocídio e crimes de guerra). Parece ter se chegado a um consenso sobre o assunto, uma vez que de maneira geral todos os países em suas propostas de definição incluem trechos como cometido por pessoa que estando em posição de controlar ou dirigir efetivamente a ação política ou militar (os países compartem da opinião de que o artigo 28 não se encaixa no crime, por ser um crime ordenado, mas não se chegou a uma decisão).

Outro ponto pacífico no tema é a presença do uso de forças armadas no cometimento do crime. Além disso, o crime de agressão envolve outros elementos que à primeira vista não parecem pertencer ou estar relacionados ao crime. Entre eles podemos citar a preparação, o planejamento e emissão de ordens do crime em questão. No Grupo Trabalho Especial sobre o crime de agressão, há um relativo acordo de que apenas se punirá a conspiração ou complô se o crime de agressão efetivamente ocorrer.

Pode-se também citar a ameaça de agressão, sobre a qual não há muito consenso: enquanto uns acham que é absurdo punir fatos não

$18 \quad$ Carta das Nações Unidas, artigo 39.

Revista Brasileira de Direito Internacional, Curitiba, v.1, n.1, jan./jun.2005 
consumados, outros acham que países pequenos podem sucumbir à ameaça de agressão de uma grande potência bélico-econômica e esta assim Ihes fazer sofrer conseqüências iguais às de uma efetiva guerra de agressão.

Há ainda outros pontos pertinentes à discussão da matéria como a lei nacional e ordens superiores. Em relação a esta última, tudo depende da adoção da restrição a pessoas com poder/controle político ou militar. Os outros dois pontos, também se encontram pouco resolvidos. O erro de tipo igualmente à questão da lei nacional, está contido no artigo 33 do Tribunal, e em ambos os casos se isenta a culpabilidade individual (resta saber se os Estados Partes manterão ou não essa disposição).

Revista Brasileira de Direito Internacional, Curitiba, v.1, n.1, jan./jun.2005 


\section{AS PROPOSTAS DE DEFINIÇÃO DO CRIME DE AGRESSÃO PARA O TPI}

No período de 16 de fevereiro de 1999 (com o início das atividades da Comissão Preparatória) a 12 de julho de 2002 (com o fim do 10ํㅜㄹóodo de Sessões da mesma Comissão), através de um processo de debate, discutiu-se sobre o tema do crime de agressão. Seu objetivo era alcançar um consenso sobre a definição para os propósitos do Tribunal e as condições para exercício de sua competência. Algumas delegações propuseram propostas de definição do crime, tanto no Período de Sessões e no específico Grupo de Trabalho sobre o crime de agressão quanto durante a Conferência de Roma.

A primeira proposta apresentada foi a do grupo de países árabes de 26 de fevereiro de 1999. Bahrein, Iraque, Líbia, Líbano, Omã, Síria, Sudão e lêmen propuseram uma boa definição do crime, constituída de uma estrutura enumerativa, ou seja, contendo uma descrição de todos os atos possíveis de se caracterizarem dentro do tipo de crime de agressão. No seu artigo $2^{\circ}$ há basicamente a lista da Resolução 3314 da Assembléia Geral. Exclui a ação do Conselho de Segurança, uma vez que com a presença dessa lista não há necessidade de uma prévia determinação por tal órgão, à Câmara de Questões Preliminares (Pre-Trial Chamber) caberia essa tarefa. Sua redação envolve além de questões globais (como a ameaça à soberania), ações específicas (em sua lista). Seu segundo artigo é exatamente igual ao artigo $3^{\circ}$ da Resolução 3314 da Assembléia Geral; sua redação, no que difere à Resolução citada, é a seguinte:

1. Aos efeitos do presente Estatuto, o crime de agressão é cometido por uma pessoa que está em condições de exercer o controle ou que pode dirigir ações políticas ou militares em seu Estado, contra outro Estado, ou que pode privar outras pessoas de seus direitos à livre determinação, à liberdade e à independência, em violação à Carta das Nações Unidas, recorrendo à força armada para ameaçar ou violar a soberania, a integridade territorial ou a independência política desse Estado ou os direitos inalienáveis dessas pessoas. $^{19}$

19 COMISIÓN PREPARATORIA DE LA CORTE PENAL INTERNACIONAL. Propuesta presentada por Bahrein, el Iraq, la Jamahirya Árabe Libia, el Líbano, Omán, la República Árabe Siria, el Sudán y Yemen. PICNICC/1999/DP.11. Tradução livre de: "A los efectos del presente Estatuto, el crimen de agresión lo comete una persona que está en condiciones de ejercer el

Revista Brasileira de Direito Internacional, Curitiba, v.1, n.1, jan./jun.2005 


\title{
De uma posição completamente oposta foi a sugestão da Federação
}

Russa de 29 de julho de 1999. Sua proposta atrela a definição à determinação prévia da existência ou não de agressão pelo Conselho de Segurança e assim não traz nenhuma enumeração como a proposta árabe. Sua definição é extremamente básica e se resume a:

\begin{abstract}
Aos efeitos do presente Estatuto e com reserva à prévia determinação do Conselho de Segurança das Nações Unidas de que o Estado interessado cometeu um ato de agressão, entender-se-á por crime de agressão qualquer dos seguintes atos: planejar, preparar ou levar a cabo uma guerra de agressão. ${ }^{20}$
\end{abstract}

Em um meio termo está a definição apresentada pela Alemanha. Atrela

o TPI a uma determinação prévia do Conselho, mas fornece uma definição muito melhor que a da sugestão russa:

1. Aos fins do presente Estatuto y com sujeição à determinação do Conselho de Segurança indicada no parágrafo $2^{\circ}$ do artigo 10 , relativa ao ato de um Estado, entender-se-á por crime de agressão qualquer dos atos seguintes cometidos por uma pessoa que esteja em posição de exercer o controle ou que pode dirigir a ação política ou militar de um Estado:

a)iniciar ou

b)executar

um ataque armado dirigido por um Estado contra a integridade territorial ou a independência política de outro Estado, quando tal ataque armado haja se empreendido em violação manifesta à Carta das Nações Unidas com o objetivo ou o resultado da ocupação militar pelas forças armadas do Estado atacante, ou a anexação mediante o uso da força, do território de outro Estado ou de parte deste.

2. Quando se haja cometido um dos atos previstos no parágrafo 1

a) a planificação

b) a preparação ou

c) a expedição de ordens

control o que puede dirigir acciones políticas o militares en su Estado, contra otro Estado, o que puede privar a otras personas de sus derechos a la libre determinación, la libertad y la independencia, en violación de la Carta de las naciones Unidas, recurriendo a la fuerza armada para amenazar o violar la soberanía, la integridad territorial o la independencia política de ese Estado o los derechos inalienables de esas personas."

20 COMISIÓN PREPARATORIA DE LA CORTE PENAL INTERNACIONAL. Propuesta presentada por la Federación de Rusia. PICNICC/1999/DP.12. Tradução livre de: "A los efectos del presente Estatuto y a reserva de la previa determinación del Consejo de Seguridad de las Naciones Unidas de que el Estado interesado ha cometido un acto de agresión, se entenderá por crimen de agresión cualquiera de los actos siguientes: planificar, preparar, iniciar o llevar a cabo una guerra de agresión."

Revista Brasileira de Direito Internacional, Curitiba, v.1, n.1, jan./jun.2005 
com respeito a isso, por uma pessoa que esteja em situação de exercer o controle ou que possa dirigir a ação política ou militar do Estado constituirá também um crime de agressão. ${ }^{21}$

Todas as propostas posteriores se alinham basicamente a um desses três grupos de posição: propostas mais progressistas como a do bloco árabe; propostas intermediárias como a alemã; e posicionamentos mais conservadores como o da Rússia. Grécia e Portugal ${ }^{22}$ propuseram uma boa definição, genérica (ou global como explicam) e que prevê a atuação do Conselho de Segurança, e também apresentaram condições para exercício da competência. Similarmente agiu a Colômbia ${ }^{23}$, em $1^{\text {o }}$ de março de 2000, e Bósnia-Hezergovina, Nova Zelândia e Romênia ${ }^{24}$, em 23/02/01 (ainda que este último grupo com uma posição um pouco mais intermediária). Cuba fez também seu pronunciamento com sua proposta "centro-esquerda" na Assembléia dos Estados Partes; sua sugestão era composta de uma definição genérica, e quanto ao Conselho de Segurança, somente previa que a falta de seu pronunciamento não impediaria a atuação do Tribunal Penal Internacional.

Como se vê pela proposta da Federação Russa, o Conselho de Segurança de forma alguma quer perder sua prerrogativa de determinar a existência de agressão prevista pela Carta da ONU. Suspeita-se que o grande

${ }_{21}$ COMISIÓN PREPARATORIA DE LA CORTE PENAL INTERNACIONAL. Propuesta presentada por Alemania. PICNICC/1999/DP.13. Tradução livre de:

"A los fines del presente Estatuto y con sujeción a la determinación del Consejo de Seguridad indicada en el párrafo 2 del artículo 10, relativa al acto de un Estado, se entenderá por crimen de agresión cualquiera de los actos siguientes cometidos por una persona que esté en posición de ejercer el control o que puede dirigir la acción política o militar de un Estado: a)iniciar o b)ejecutar,

un ataque armado dirigido por un Estado contra la integridad territorial o la independencia politica de otro Estado, cuando dicho ataque armado se haya emprendido en violación manifiesta de la Carta de las Naciones Unidas con el objetivo o el resultado de la ocupación militar por las fuerzas armadas del Estado atacante, o la anexión mediante el uso de la fuerza, del territorio de otro estado o de parte de éste.

2. Cuando se haya cometido uno de los actos previstos en el párrafo 1: a) la planificación b) la preparación o c) la expedición de órdenes a ese respecto por una persona que esté en situación de ejercer el control o que pueda dirigir la acción política o militar del Estado constituirá también um crimen de agresión."

${ }_{22}$ COMISIÓN PREPARATORIA DE LA CORTE PENAL INTERNACIONAL. Propuesta presentada por Grecia y Portugal. PCNICC/2000/WGCA/DP.5.

23 COMISIÓN PREPARATORIA DE LA CORTE PENAL INTERNACIONAL. Propuesta presentada por Colombia sobre la definición del crimen de agresión y de la competencia de la Corte respecto a dicho crimen. PICNICC/2000/WGCA/DP.1.

24 COMISIÓN PREPARATORIA DE LA CORTE PENAL INTERNACIONAL. Propuesta presentada por Bosnia y Hezergovina, Nueva Zelanda y Rumanía . PCNICC/2001/WGCA/DP.1.

Revista Brasileira de Direito Internacional, Curitiba, v.1, n.1, jan./jun.2005 
medo dos membros do Conselho de Segurança seja de que, na impossibilidade de poder vetarem a remissão de um caso para o TPI decidindo pela não existência de agressão, as ações de seus enviados a missões de paz da ONU sejam consideradas em certos casos atos de agressão, e conseqüentemente aos dirigentes políticos possa ser imputado o crime de agressão ${ }^{25}$. Os Estados Unidos assumiram posição rígida nesse sentido, e inclusive foram contra a inclusão desse crime no Estatuto, compativelmente com sua intenção de minimizar o quanto possível o âmbito de atuação material do TPI. No caso dos EUA, a situação é ainda mais séria por causa de suas políticas unilaterais, como por exemplo no caso do Iraque (em que desafiou o próprio Conselho). Oito dos dez membros não-permanentes (Argentina, Benin, Brasil, Dinamarca, Japão, Filipinas, Tanzânia e Argélia) não fizeram proposta alguma, e o dois que fizeram (Grécia e Romênia) não se distanciaram da proposta russa. Igualmente, agiram os componentes do G4; Brasil, Japão, Índia nada sugeriram, e Alemanha fez uma proposta que em termos de definição do crime não é tão "conservadora" mas que de forma alguma destitui o Conselho da função de prévia determinação.

Defrontando-se com interesses tão díspares, as discussões durante a Conferência não foram muito rentáveis no sentido de se chegar a um acordo, como ocorreu para os demais crimes. Chegando-se perto do fim da Conferência não se havia alcançado uma conclusão sobre a questão. Então, sugeriu-se a inclusão apenas de facto do crime de agressão e sua posterior definição, e o grupo dos Países não Alinhados propôs, em 2 de julho de 2002,

\footnotetext{
25 Nesse sentido afirma KHERAD, Rahim (Definition de l'Agression et Statut de Rome. Revue Générale de Droit international Public): "Durante a Conferência de Roma, os Estados enviantes (provedores) de tropas às operações de manutenção da paz, que se tratam dos membros permanentes ou aqueles da Aliança Atlântica, sustentavam com firmeza que a qualificação de um ato de agressão pelo Conselho constituía uma condição prévia e indispensável a toda remissão de uma situação perante o TPI". E mais: "os estados engajados nas operações de manutenção da paz, notavelmente os membros permanentes, defenderam uma definição restritiva, afim de evitar que seus nacionais não sejam levados perante a Corte." Traduções livres de: "Lors de la Conférence de Rome, les États pourvoyeurs de troupes aux óperations de maintien de la paix, qu'il s'agisse des membres permanents ou de ceux de I'Alliance Atlantique, soutenaient avec fermeté que la qualification d'un acte d'agression par le Conseil constituiait une condition préalable et indispencsable à tout renvoi d'une situation devant la CPI." Página 346 e "les États engagés dans les opérations de maintien de la paix, notamment les membres permanents, prônèrent une définition restrictive, afin d'éviter que leurs ressortissants ne soient traduits devant la Cour." Pággina 345
}

Revista Brasileira de Direito Internacional, Curitiba, v.1, n.1, jan./jun.2005 
uma continuação do trabalho através de um Grupo de Trabalho Especial sobre o crime de agressão. O último período de sessões (4ํ) ocorreu no Instituto Liechtenstein de Investigações sobre a Livre Determinação (Universidade de Princeton em New Jersey) sob a presidência do Embaixador Christian Wenaweser de Liechtenstein, de 13 a 15 de junho de 2005. Com esse grupo as discussões têm evoluído, mas se parece estar longe de alcançar um consenso nos pontos mais polêmicos.

Revista Brasileira de Direito Internacional, Curitiba, v.1, n.1, jan./jun.2005 


\section{CONSIDERAÇÕES FINAIS}

Qualquer definição de definição que se venha a adotar deve ter como parâmetro o respeito fundamental aos princípios do Direito Penal Internacional. Entre eles figura o princípio do nullum crimen nulla pœna sine lege; o respeito a ele deve se dar sob dois aspectos: o da competência temporal e o do uso de uma definição não demasiadamente restritiva.

Deve-se estabelecer que o Tribunal Penal Internacional somente poderá exercer competência sobre o crime de agressão a partir da entrada em vigor da nova definição (o que deve estar contido expressamente no texto), refutando-se a posição de que o poderia fazer a partir da entrada em vigor do Estatuto de Roma. Afinal, seria absurdo produzir uma criminalização sem a necessária existência de uma definição do crime e seus elementos.

Uma definição ideal deveria se encaixar nos moldes da proposta do bloco dos Estados árabes: uma parte inicial que contenha todos os elementos descritos no artigo $1^{\circ}$ da proposta (dentre tais, destaca-se a restrição do crime a pessoas com poder/controle político ou militar e o uso de força armada) e uma segunda parte que contenha uma enumeração dos atos que se enquadram no tipo do crime de agressão.

Ao mesmo tempo que uma definição de agressão enumerativa-taxativa favorece não incorrer no problema do nullum crimen nulla pœna sine lege e no problema de dotar o Tribunal de demasiado poder, pode limitar por demais o âmbito de ação deste. Portanto, defende-se uma definição que englobe os dois pólos; ou seja, uma enumeração não taxativa com expressão semelhante à que se encontra no artigo $7^{\circ}$ (crime conta a humanidade), parágrafo $1^{\circ}$, alínea $\mathrm{k}$ :

k) Outros atos desumanos de caráter semelhante, que causem intencionalmente grandes sofrimentos, ou atentem gravemente contra a integridade física ou a saúde mental ou física. ${ }^{26}$

26 Tradução livre de: $\mathrm{k}$ ) Otros actos inhumanos de carácter similar que causen intencionalmente grandes sufrimientos o atenten gravemente contra la integridad física o la salud mental o física.

Revista Brasileira de Direito Internacional, Curitiba, v.1, n.1, jan./jun.2005 
A definição do crime deve ser encarada como uma emenda ao Estatuto, respeitando, portanto, as disposições do artigo $121^{27}$. Não há como tratar especialmente ao crime de agressão uma vez que o artigo acima citado dispõe em seus parágrafos 5 e 6 que:

\begin{abstract}
5. As emendas ao artigo $5^{\circ}, 6^{\circ}, 7^{\circ}$ e $8^{\circ}$ do presente Estatuto entrarão em vigor unicamente para os Estados Partes que as tenham aceitado, um ano após o depósito dos seus instrumentos de ratificação ou de aceitação. O Tribunal não exercerá sua competência relativamente a um crime abrangido pela emenda quando houver sido cometido por nacionais ou no território de um Estado Parte que não haja aceitado a alteração.

6. Se uma emenda houver sido aceita por sete oitavos dos Estados Partes nos termos do parágrafo 4, o Estado Parte que não a tenha aceitado poderá denunciar o Estatuto com efeito imediato, não obstante o disposto no parágrafo 10 do artigo 127 , mas sem prejuízo do disposto no parágrafo $2^{\circ}$ do artigo 127 , mediante notificação da sua retirada feita no mais tardar um ano após a entrada em vigor da emenda. ${ }^{28}$
\end{abstract}

Ao mesmo tempo que a não adoção de uma vinculação obrigatória possa vir a não abranger todos os países que hoje são Estados Partes, não se pode desrespeitar o disposto e aceito no artigo 121, mesmo porque se deve levar em consideração que alguns Estados possam ter aceitado o estatuto em virtude destas condições. Nesse aspecto entra novamente o papel do consenso.

27

Estatuto de Roma artigo 121, parágrafos 2, 3 e 4:

2. Decorridos pelo menos três meses após a data de notificação, a Assembléia dos Estados Partes decidirá na reunião seguinte, por maioria dos presentes e votantes, se deverá examinar a proposta, o que poderá fazer diretamente ou com uma convocação de uma Conferência de Revisão se a questão suscitada o justificar.

3. A aprovação de uma emenda em uma reunião da Assembléia dos Estados Partes ou em uma Conferência de Revisão, na qual seja possível chegar a um consenso, requerirá uma maioria de dois terços dos Estados Partes.

4. Sem prejuízo do disposto no parágrafo 5 , qualquer alteração entrará em vigor, para todos os Estados Partes, um ano depois de que sete oitavos destes hajam depositado junto ao Secretário-Geral da Organização das Nações Unidas seus respectivos instrumentos de ratificação ou de adesão.

28

Tradução livre da versão original em espanhol do Estatuto de Roma.

Tradução livre de:

5. Las enmiendas a los artículos 5, 6, 7 y 8 del presente Estatuto entrarán en vigor únicamente respecto de los Estados Partes que las hayan aceptado un año después del depósito de sus instrumentos de ratificación o aceptación. La Corte no ejercerá su competencia respecto de un crimen comprendido en la enmienda cuando haya sido cometido por nacionales o en el territorio de un Estado Parte que no haya aceptado la enmienda.

6. Si una enmienda ha sido aceptada por los siete octavos de los Estados Partes de conformidad con el párrafo 4, el Estado Parte que no la haya aceptado podrá denunciar el presente Estatuto con efecto inmediato, no obstante lo dispuesto en el párrafo 1 del artículo 127 pero con sujeción al párrafo 2 de dicho artículo, mediante notificación hecha a más tardar un año después de la entrada en vigor de la enmienda.

Revista Brasileira de Direito Internacional, Curitiba, v.1, n.1, jan./jun.2005 
Em relação à questão talvez central do assunto aqui abordado (a atuação do Conselho de Segurança), enxerga-se que seria ideal a adoção de uma definição em que não se previsse atuação alguma do Conselho na determinação prévia da existência do crime de agressão conforme jurisprudência da Corte Internacional de Justiça no caso Nicarágua ${ }^{29}$. Conforme diz Rahim Kherad tal Corte

\begin{abstract}
"rejeitou o argumento dos Estados Unidos conforme o qual a agressão invocada pela Nicarágua, nos termos do artigo 39, somente podia ser conhecida pelo Conselho de Segurança. A CIJ, para demonstrar a legitimidade de sua posição, especifica que 'a Corte não foi demandada a dizer se o Conselho de Segurança cometeu um erro, nem se a maneira de votar de seus membros esteve em algo contrária ao Direito. A Corte é solicitada a se pronunciar sobre certos aspectos de uma questão que foi também examinada pelo Conselho, o que é perfeitamente conforme a sua situação de órgão judiciário principal das Nações Unidas'." ${ }^{30}$
\end{abstract}

Havendo, portanto, tal Corte refutado a competência exclusiva do Conselho para determinar a existência de agressão. Defende-se igual posição, mesmo porque o Conselho tem demonstrado na prática que mesmo em casos de clara existência de agressão não determina sua existência, preferindo utilizar termos como ruptura da paz ou invasão ${ }^{31}$. Porém, ao mesmo tempo, vêse que dificilmente se alcançará tal consenso privando-o de qualquer atuação. Ainda assim há que se buscar a menor atuação possível de tal órgão político ${ }^{32}$ numa corte que pretende ser imparcial, dotando o Tribunal de meios (caso a atuação do conselho não seja totalmente refutada) para que sua tarefa não seja de todo minada.

\footnotetext{
29 Ver melhor em <http://www.icj-cij.org/cijwww/cinformationgenerale/cbbook/cbook81.52.htm>.

30 KHERAD, Rahim. Definition de l'Agression et Statut de Rome. Revue Générale de Droit international Public . Página 358. Tradução livre de: "a rejeté l'argument des États-Unis selon lequel l'agression invoquée par le Nicaragua, aux termes de l'article 39, ne pouvait être connue que du Conseil de sécurité. La ClJ, pour prouver le bien-fondé de sa position, précise qu' 'il n'est pas demandé à la Cour de dire que le Conseil de sécurité a commis un erreur, ni que la manière de voter des membres du Conseil ait été en rien contraire au droit. La Cour est priée de se prononcer sur certains aspects juridiques d'une question qui a été aussi examinée par le Conseil, ce qui est parfaitement conforme à sa situation d'organe judiciaire principal des Nations unies'."

${ }_{31}$ Como nos exemplos da guerra da Coréia (Coréia do Norte v. Coréia do Sul), da guerra das Malvinas (Reino Unido v. Argentina) e da invasão do Kuwait pelo Iraque.

32 Como defendem os países não-alinhados e os dos like-minded group.
}

Revista Brasileira de Direito Internacional, Curitiba, v.1, n.1, jan./jun.2005 


\section{REFERÊNCIAS}

BUGNION, François. Guerra justa, guerra de agresión y derecho internacional humanitArio. Revista Internacional de la Cruz roja, no 847. Disponível na Internet: <http://www.icrc.org/Web/spa/sitespa0.nsf/iwpList84/A1317899924A9D04C125 6DE200316C9B $>$ vista em 23/10/2005.

COMISIÓN PREPARATORIA DE LA CORTE PENAL INTERNACIONAL. Propuesta presentada por Alemania. PICNICC/1999/DP.13. 30 de julho de 1999.

COMISIÓN PREPARATORIA DE LA CORTE PENAL INTERNACIONAL. Propuesta presentada por Bahrein, el Iraq, la Jamahirya Árabe Libia, el Líbano, Omán, la República Árabe Siria, el Sudán y Yemen. PICNICC/1999/DP.11. 26 de fevereiro de 1999.

COMISIÓN PREPARATORIA DE LA CORTE PENAL INTERNACIONAL. Propuesta presentada por Bosnia y Hezergovina, Nueva Zelanda y Rumanía. PCNICC/2001/WGCA/DP.1. 23 de fevereiro de 2001.

COMISIÓN PREPARATORIA DE LA CORTE PENAL INTERNACIONAL. Propuesta presentada por Colombia sobre la definición del crimen de agresión y de la competencia de la Corte respecto a dicho crimen.

PICNICC/2000/WGCA/DP.1. 1. de março de 2000.

COMISIÓN PREPARATORIA DE LA CORTE PENAL INTERNACIONAL. Propuesta presentada por Grecia y Portugal. PCNICC/2000/WGCA/DP.5. 28 de novembro de 2000.

COMISIÓN PREPARATORIA DE LA CORTE PENAL INTERNACIONAL. Propuesta presentada por la Federación de Rusia. PICNICC/1999/DP.12. 29 de julho de 1999.

GEWERH, Joachim. Defining Aggression for the International Criminal Court: A Proposal. Disponível na Internet em formato pdf no site:

$<$ http://web.uct.ac.za/depts/pbl/gewehr.pdf $>$ vista em 23/10/2005.

KHERAD, Rahim. Definition de l'Agression et Statut de Rome. Revue Générale de Droit international Public. Paris: [s.n.], tome 109/2005/2, p. 331-360, 2005.

LAWYERS COMITEE FOR HUMANS RIGHT. Establishing an International Criminal Court: Major Unresolved Issues in the Draft Statute. Disponível na Internet em formato pdf na página: < http://www.iccnow.org/romearchive/papers/RomeTreaty/LCHRUnresolvedlssue s.pdf> vista em 23/10/2005.

Revista Brasileira de Direito Internacional, Curitiba, v.1, n.1, jan./jun.2005 
MELLO, Celso Duvivier de Albuquerque. Curso de Direito Internacional Público. $12^{\mathrm{a}}$ ed. rev. e aum. Rio de Janeiro: Renovar, 2000.

NOTARPIETRO, Massimo. La Corte Penale Internazionale Permanente per la Repressione dei Più Gravi Crimini di Diritto Internazionale. Disponível na Internet em formato pdf na página:<http://files.studiperlapace.it/docs/notarpietro.pdf> vista em 20/11/2005.

PIERCE, Rachel. Which of the Preparatory Commission's Latest Proposals for the Definition of the Crime of Aggression and Exercise of Jurisdiction Should Be Adopted into the Rome Satute of the International Criminal Court? Disponível na Internet em formato pdf na página:

$<$ http://www.law2.byu.edu/jpl/volumes/vol15 no2/PeirceFinal.pdf $>$ vista em 20/11/2005.

Revista Brasileira de Direito Internacional, Curitiba, v.1, n.1, jan./jun.2005 